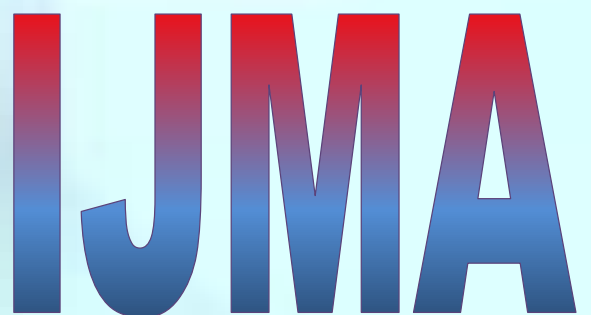

INTERNATIONAL

Journal of MEdical

\section{ARTS}

Volume 3, Issue 1 (Winter 2021)

http://ijma.journals.ekb.eg/

Print ISSN: 2636-4174

Online ISSN: 2682-3780

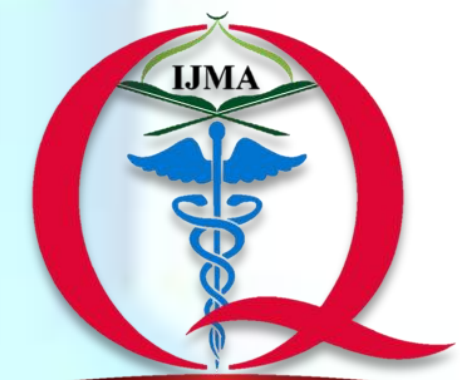

International Jounnal of Medical Arts

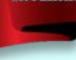





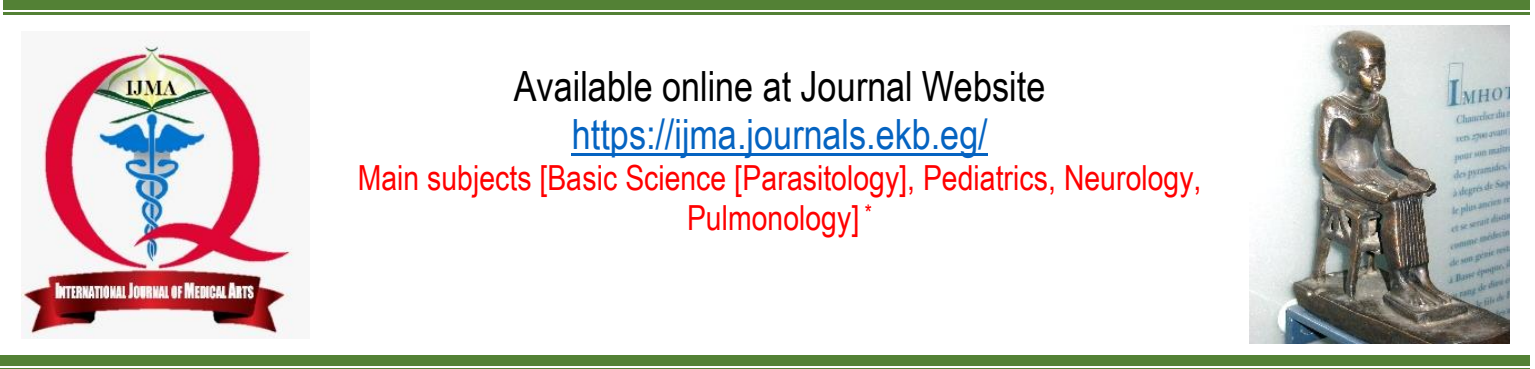

Original article

\title{
Toxocariasis; A Neglected Tropical Disease. Association with Asthma, Chronic Urticaria, and Unexplained Neurologic Manifestations Among Children
}

\author{
Khaled A. Temsah[1]; Mostafa E. Mostafa [1]; Hany El-Khaleegy [2]; Atef W. El Rifai [3], Sherief M. Al \\ Shazly ${ }^{[4]}$, Mona AD Abd Rabbo ${ }^{[5]}$
}

Departments of Parasitology $\left[{ }^{[1]}\right.$, Pediatrics ${ }^{[2]}$, Chest Diseases ${ }^{[3]}$, and Neurology ${ }^{[4]}$, Damietta Faculty of Medicine, Al-Azhar University, Egypt

Department of Parasitology, Faculty of Medicine for Girls, Al-Azhar University, Egypt [5]

Corresponding author: Khaled A. Temsah

Email: drkhaled2008@yahoo.com

Received at: October 15, 2020; Revised at: November 21, 2020; Accepted at: November 21, 2020

DOI: 10.21608/ijma.2020.46359.1192

ABSTRACT
Background: The link between parasitic infestation and allergic diseases or unexplained neurologic manifestations
was hypothesized, especially in children. However, the debate continues regarding this link.
Aim of the work: To determine the seroprevalence of toxocariasis in children with different allergic diseases [bronchial
asthma and skin allergy], besides the unexplained neurological manifestations [epilepsy and focal neurologic
deficits] in children.
Patients and methods: Children with bronchial asthma [ 40 children], skin allergy [ 40 children], and unexplained
neurological manifestations [epilepsy and focal neurologic deficits], [ 40 children] were included. All underwent
a full history taking, clinical examination, lab investigations, and seropositivity determination for Toxocara canis.
Results: Eosinophilia was reported in $22.5 \%, 30.0 \%$, and $17.5 \%$ of asthma, skin, and unexplained neurological
manifestations groups, respectively. In patients with asthma, the prevalence of toxocariasis was $15.0 \%$; in skin
disease, it was $7.5 \%$, and in unexplained neurological manifestations, it was $12.5 \%$. There was no significant
difference between positive and negative toxocariasis regarding patient demographics. But there was a
significant increase in contact with pets, chronic urticaria, lymph nodes involvement, and eosinophilia in positive
when compared to negative groups.
Conclusion: The association between Toxocara canis infection and allergic diseases such as bronchial asthma,
chronic urticaria, and unexplained neurological manifestations [epilepsy and focal neurologic deficits] was
confirmed in the present work. The contact with dogs and cats [pets] was the major determinant risk factor
explaining such association. Prospective cohort studies were warranted to examine the cause-effect
relationship.

Keywords: Bronchial asthma; Children; Toxocariasis; Epilepsy; Chronic urticaria; Pets.

This is an open-access article registered under the Creative Commons, ShareAlike 4.0 International license [CC BY-SA 4.0] [https://creativecommons.org/licenses/by-sa/4.0/legalcode]

Please cite this article as: Temsah KA, Mostafa ME, El-Khaleegy H, El Rifai AW, Al shazly SM, Abd Rabbo MAD. Toxocariasis; A Neglected Tropical Disease. Association with Asthma, Chronic Urticaria and Unexplained Neurologic Manifestations Among Children. IJMA 2021; 3[1]: 922-929. DOI: 10.21608/ijma.2020.46359.1192

* Main subject and any subcategories have been classified according to the research topic. 


\section{INTRODUCTION}

Human toxocariasis is a worldwide zoonotic helminthic infection caused by two species of the ascarid worms, Toxocara canis and, to a lesser extent, T. cati. Also, Toxocara leonina, which causes mixed infections in cats and dogs, can infect humans; therefore, it has zoonotic and public health importance ${ }^{[1-2]}$. There are other species of Toxocara that rarely or never infecting humans [3].

Toxocariasis was first described in the 1950s and considered uncommon in children. However, several research types reported that Toxocara is the commonest worm worldwide and is more frequent in children with an age group of 3 to 12 years ${ }^{[4-6]}$. The infection is transmitted to humans by ingesting embryonated eggs from soil [geophagia, pica], unclean hands, uncooked vegetables, and larvae from raw giblets. Eating soil [pica] was a risk factor for Toxocariasis. Toxocara larvae reach the liver, lungs, and other body organs by penetrating the intestinal mucosa and migrating to different organs. The infection morbidity depends mainly on host immune response and parasite burden ${ }^{[1,7]}$.

The body responds through immune reactions, resulting in local inflammation, eosinophilia, and cytokine production[8]. According to Toxocara larvae migration through tissues, human toxocariasis is classified into visceral, cerebral, ocular, and covert toxocariasis[9].

The clinical presentation of toxocariasis in human subjects varies from asymptomatic to severe disease[10]. However, many infections were underdiagnosed due to the asymptomatic, mild, or non-specific clinical features of the infection[1]. Asymptomatic human toxocariasis could be presented with impaired cognitive functions ${ }^{[11]}$ and immunomodulation. The pulmonary toxocariasis was associated with asthma like symptoms [12]. The plausible role of parasitic infections as a trigger or a cause of asthma is not well investigated[13]. However, toxocariasis has been proposed as a probable etiology of asthma [14-15].

Bronchial asthma is one of the most common chronic diseases challenging health care providers all over the world. It increased progressively during the last decades due to environmental and lifestyle risk factors ${ }^{[16]}$.

The association between toxocariasis and epilepsy was reported, as there were high seropositivity rates for Toxocara among epileptic patients. However, the evidence needs further investigations ${ }^{[17]}$; an accurate estimation of the link between Toxocara and epilepsy is needed due to the high incidence of toxocariasis worldwide [18]. Furthermore, the dermatological manifestations in intestinal toxocariasis presented as rash, pruritus, eczema, panniculitis, urticaria, and vasculitis have also been reported[19].

The Western blotting assay combines the high sensitivity of the immune-enzymatic tests with the high resolution of sodium dodecyl sulfatepolyacrylamide gel electrophoresis [SDS PAGE]. This method has been successfully used to confirm the confirmatory serodiagnosis of various parasitic diseases, including Toxocariasis, schistosomiasis, hydatidosis, and cysticercosis taeniasis, fasciolosis, and strongyloidiasis. Nowadays, in patients with suspected toxocariasis, immunoblot assay is useful to confirm any positive serum by the ELISA test [where pre-absorption is not carried out][18].

\section{AIM OF THE WORK}

The present study aimed to determine the seroprevalence of toxocariasis in children with different allergic diseases [bronchial asthma and skin allergy] and unexplained neurological manifestations [epilepsy and focal neurologic deficits].

\section{SUBJECTS AND METHODS}

This study was carried out at Al-Azhar University hospital and the department of Parasitology, Faculty of Medicine, Al-Azhar University [Damietta], Egypt. It included 120 children, age 3-16 years, who were evaluated and followed up in the Neurology, Pediatrics, Dermatology, and Chest disease departments, during the period from August 2018 to August 2019. In this study, we focus on chronic asthma, particular skin manifestations [chronic urticaria [CU] and pruritis/prurigo] and cryptogenic epilepsy and focal neurological lesions regarding their clinical description, diagnosis and treatment to 
investigate the probable relationship between Toxocara seropositivity from one side and asthma, chronic urticaria, cryptogenic epilepsy and focal neurological lesions from the other side.

Informed consent was obtained from the parents/guardians of children after a simple and clear explanation of the research object, procedure, and the liberty to drop out. All children were subjected to full history taking, full physical examination and were examined for seropositivity for Toxocara antibodies by immunoblot. The following data were collected for each participant [age, sex, residence, contact with pets, and geophagia].

We included patients aged 3-16 years of age, who had moderate to severe bronchial asthma [ 40 children], pruritus/prurigo [20 patients], and chronic urticaria [20 patients]. Chronic urticaria is defined as an outbreak of edematous, projecting, well delimited, and rounded papules, persisting for more than 6 weeks. In addition, 40 children with unexplained neurological manifestations were included. The cryptogenic epilepsy was diagnosed based on a negative family history of epilepsy, no history of head trauma, no previous brain surgery, meningitis or encephalitis, and normal electroencephalogram [EEG] and magnetic resonance imaging [MRI].

The exclusion criteria were: children positive for nematodes infection by stool examination [e.g., ascariasis, enterobiasis] to overcome crossreactivity to toxocariasis, and acute symptomatic seizures, specific seizure patterns, and epileptic syndromes.

After full clinical evaluation, the samples were drawn for laboratory workup, including complete blood count [eosinophilia], Immunoblot [for Toxocara canis $\lg \mathrm{G}]$. Finally, a microscopic stool examination had been performed.

\section{Sample Collection:}

Feces samples were collected from patients for three consecutive days and evaluated for nematode eggs. Positive cases were excluded to avoid cross-reaction possibility.

Blood samples: $5 \mathrm{ml}$ of venous blood samples were collected from diseased children, and healthy controls included in the study and placed in 2 tubes. One is containing anticoagulant for CBC with differential leukocytes count looking mainly for eosinophilia corresponded to levels above $400 / \mathrm{mm}^{3}$. This test was made by [Sysmex XP$300^{\mathrm{TM}}$ Automated Hematology Analyzer]. The $2^{\text {nd }}$ tube is a serology collection tube where $3 \mathrm{ml}$ whole blood was collected, centrifuged, and serum separated and collected in aliquots for serologic testing.

\section{Serological Investigation:}

Collected serum samples were stored at $-20^{\circ} \mathrm{C}$ until used. These samples were then tested for anti-Toxocara $\lg G$. The $\lg G$ detection was done using Toxocara Western Blot [WB] IgG [LDBIO Diagnostic, Lyon, France], which detects antibodies against the excretory/secretory antigen of the Toxocara canis larvae. A sample of $10 \mu \mathrm{l}$ is required for Toxocara WB $\lg G$ testing. Positive and negative controls were included in the kit.

Data analysis: Quantitative data were presented as mean \pm standard deviation [SD] and groups compared by independent samples student $[t]$ test, while categorical variables expressed as frequency and percentages and groups compared by Chi-square test. P-value < 0.05 was considered significant, and all data processing and analysis were carried out by statistical package for social sciences [SPSS] version 16 [SPSS Inc., Chicago, Illinois, USA].

\section{RESULTS}

The patient's age ranged from 3 to 13 years with no significant difference between studied groups [the mean age was $8.10 \pm 2.15,7.30 \pm$ 2.33 , and $7.27 \pm 2.22$ years in asthma, skin, unexplained focal neurologic lesions, and unexplained neurologic manifestations groups, respectively]. Also, there was no significant difference between the groups regarding sex distribution [males represented $65.0 \%, 55.0 \%$, and $57.5 \%$ of asthma, skin, and unexplained neurologic manifestations groups, respectively]. Rural area predominates in the studied groups $[72.5 \%, 75.0 \%$, and $77.5 \%$ of asthma, skin, and unexplained neurologic manifestations groups successively]. The contact with pets was reported in more than $80.0 \%$ of all groups [80.0\% in the 
asthma group, $82.5 \%$ in the skin group, and $85.0 \%$ of the unexplained neurologic manifestations group]. Finally, geophagia was reported in $15.0 \%$, $12.5 \%$, and $12.5 \%$ of asthma, skin allergy, and unexplained neurologic manifestations groups [Table 1].

In the asthma group, the chronic cough was reported in $82.5 \%$, wheezy chest in $100.0 \%$ of patients, and dyspnea in $47.5 \%$; while in the skin group, $50 \%$ had chronic urticaria and $50 \%$ had pruritus. Finally, unexplained neurologic manifestations were $92.5 \%$ cryptogenic epilepsy and $7.5 \%$ unexplained focal neurologic lesions. Besides lymph node involvement was reported in only one patient in the asthma group, while eosinophilia was reported in $22.5 \%, 30.0 \%$ and $17.5 \%$ of asthma, skin unexplained neurologic manifestations groups respectively. In patients with asthma, the incidence of asymptomatic toxocariasis was $15.0 \%$, in skin disease, the incidence was $7.5 \%$ and in patients with unexplained neurologic manifestations, it was $12.5 \%$ [Table 2].

In the present study, there was no significant difference between positive and negative toxocariasis regarding patient age, sex, residence, geophagia, chronic cough, wheezing, dyspnea, cryptogenic epilepsy, and unexplained focal neurologic lesions. On the other hand, there was a significant increase of contact with pets, chronic urticaria, lymph node involvement, and eosinophilia in positive when compared to negative groups [Table 3]

Table [1]: Patient demographics, history of contact with pets and geophagia among studied groups

\begin{tabular}{|c|c|c|c|c|c|c|}
\hline \multicolumn{2}{|c|}{ Variable } & $\begin{array}{l}\text { Asthma } \\
{[n=40]}\end{array}$ & $\begin{array}{l}\text { Skin allergy } \\
{[n=40]}\end{array}$ & $\begin{array}{c}\text { Unexplained } \\
\text { neurologic } \\
\text { manifestation } \\
{[n=40]} \\
\end{array}$ & t- test & $P$ value \\
\hline \multicolumn{2}{|c|}{ Age [mean $\pm S D$; range] } & $\begin{array}{c}8.10 \pm 2.15 \\
5.0-13.0\end{array}$ & $\begin{array}{l}7.30 \pm 2.33 \\
3.0-12.50\end{array}$ & $\begin{array}{c}7.27 \pm 2.22 \\
4.0-13.0\end{array}$ & 1.75 & $0.18[\mathrm{~ns}]$ \\
\hline \multirow{2}{*}{ Sex } & Male & $26[65.0 \%]$ & $22[55.0 \%]$ & $23[57.5 \%]$ & \multirow{2}{*}{0.89} & \multirow{2}{*}{$0.63[\mathrm{~ns}]$} \\
\hline & Female & $14[35.0 \%]$ & $18[45.0 \%]$ & $17[42.5 \%]$ & & \\
\hline \multirow{2}{*}{ Residence } & Rural & $29[72.5 \%]$ & $30[75.0 \%]$ & $31[77.5 \%]$ & \multirow{2}{*}{0.26} & \multirow{2}{*}{$0.87[\mathrm{~ns}]$} \\
\hline & Urban & $11[27.5 \%]$ & $10[25.0 \%]$ & $9[22.5 \%]$ & & \\
\hline \multirow{2}{*}{$\begin{array}{l}\text { Contact with } \\
\text { pets }\end{array}$} & Yes & $32[80.0 \%]$ & $33[82.5 \%]$ & $34[85.0 \%]$ & \multirow{2}{*}{0.34} & \multirow{2}{*}{$0.84[\mathrm{~ns}]$} \\
\hline & No & $8[20.0 \%]$ & $7[17.5 \%]$ & $6[15.0 \%]$ & & \\
\hline \multirow{2}{*}{ Geophagia } & Yes & $6[15.0 \%]$ & $5[12.5 \%]$ & $5[12.5 \%]$ & \multirow{2}{*}{0.14} & \multirow{2}{*}{ 0.93[ns] } \\
\hline & No & $34[85.0 \%]$ & $35[87.5 \%]$ & $35[87.5 \%]$ & & \\
\hline
\end{tabular}

Table [2]: Clinical and laboratory manifestations among studied populations.

\begin{tabular}{|l|c|c|c|c|c|}
\hline \multicolumn{1}{|c|}{ Variable } & Asthma [n=40] & $\begin{array}{c}\text { Skin allergy } \\
{[\mathrm{n}=40]}\end{array}$ & $\begin{array}{c}\text { Unexplained } \\
\text { neurologic } \\
\text { manifestation } \\
{[\mathrm{n}=40]}\end{array}$ & $\begin{array}{c}\mathrm{t}- \\
\text { test }\end{array}$ & P value \\
\hline Chronic cough & $33[82.5 \%]$ & - & - & - & - \\
\hline Wheezing & $40[100.0 \%]$ & - & - & - & - \\
\hline Dyspnea & $19[47.5 \%]$ & - & - & - & - \\
\hline Chronic urticaria & - & $20[50.0 \%]$ & - & - & - \\
\hline Pruritus & - & $20[50.0 \%]$ & - & - & - \\
\hline Cryptogenic epilepsy & - & - & $37[92.5 \%]$ & - & - \\
\hline $\begin{array}{l}\text { Unexplained Focal } \\
\text { neurological lesions }\end{array}$ & - & - & $3[7.5 \%]$ & - & - \\
\hline Lymph nodes involvement & $1[2.5 \%]$ & $0[0.0 \%]$ & $0[0.0 \%]$ & 2.01 & $0.36[\mathrm{~ns}]$ \\
\hline Eosinophilia & $9[22.5 \%]$ & $12[30.0 \%]$ & $7[17.5 \%]$ & 1.77 & $0.41[\mathrm{~ns}]$ \\
\hline $\begin{array}{l}\text { Toxocara Immunoblot } \\
\text { Antibody positivity }\end{array}$ & $6[15.0 \%]$ & $3[7.5 \%]$ & $5[12.5 \%]$ & 1.13 & $0.56[\mathrm{~ns}]$ \\
\hline
\end{tabular}


Table [3]: Comparison between positive and negative toxocariasis among studied children.

\begin{tabular}{|c|c|c|c|c|c|}
\hline \multicolumn{2}{|c|}{ Variable } & Positive [n=14] & Negative [ $n=106]$ & T test & $P$ value \\
\hline \multicolumn{2}{|c|}{$\begin{array}{l}\text { Age [mean } \pm S D ; \\
\text { range] }\end{array}$} & $\begin{array}{c}8.07 \pm 2.52 \\
5.0-13.0\end{array}$ & $\begin{array}{c}7.49 \pm 2.21 \\
3.0-13.0\end{array}$ & 0.91 & $0.36[\mathrm{~ns}]$ \\
\hline \multirow{2}{*}{ Sex } & Male & $8[57.1 \%]$ & $63[59.4 \%]$ & \multirow{2}{*}{0.02} & \multirow{2}{*}{$0.87[\mathrm{~ns}]$} \\
\hline & Female & 6 [42.9\%] & $43[40.6 \%]$ & & \\
\hline \multirow[b]{2}{*}{ Residence } & Rural & $12[85.7 \%]$ & $78[73.6 \%]$ & \multirow{2}{*}{0.97} & \multirow[b]{2}{*}{$0.32[\mathrm{~ns}]$} \\
\hline & Urban & $2[14.3 \%]$ & 28 [26.4\%] & & \\
\hline \multicolumn{2}{|c|}{ Contact with pets } & $14[100.0 \%]$ & $85[80.2 \%]$ & 5.76 & $0.016^{*}$ \\
\hline \multicolumn{2}{|c|}{ Geophagia } & $4[28.6 \%]$ & $12[11.3 \%]$ & 3.18 & 0.07 \\
\hline \multicolumn{2}{|c|}{ Chronic cough } & $6[100.0 \%]$ & $27[79.4 \%]$ & 1.49 & 0.22 \\
\hline \multirow{2}{*}{\multicolumn{2}{|c|}{ Wheezing }} & $6[100.0 \%]$ & $34[100.0 \%]$ & - & - \\
\hline & Dyspnea & $3[50.0 \%]$ & $16[47.1 \%]$ & 0.02 & 0.89 \\
\hline \multicolumn{2}{|c|}{ Chronic urticaria } & $3[100.0 \%]$ & $17[45.9 \%]$ & 4.40 & $0.036^{*}$ \\
\hline \multicolumn{2}{|c|}{ Pruritus } & $0[0.0 \%]$ & $20[54.1 \%]$ & 4.40 & $0.036^{*}$ \\
\hline \multicolumn{2}{|c|}{ Cryptogenic epilepsy } & $4[80.0 \%]$ & $33[94.3 \%]$ & 1.28 & 0.25 \\
\hline \multicolumn{2}{|c|}{$\begin{array}{l}\text { Unexplained focal neurological } \\
\text { lesions }\end{array}$} & 1 [20.0\%] & 2 [5.7\%] & 1.28 & 0.25 \\
\hline \multicolumn{2}{|c|}{ Lymph nodes involvement } & $1[7.1 \%]$ & $0[0.0 \%]$ & 7.63 & $0.006^{*}$ \\
\hline \multicolumn{2}{|c|}{ Eosinophilia } & $7[50.0 \%]$ & $21[19.8 \%]$ & 6.30 & $0.012^{*}$ \\
\hline
\end{tabular}

\section{DISCUSSION}

Toxocara was reported as one of the wide world distributed geoparasites ${ }^{[2]}$. About $21 \%$ of the population was infected with one or more intestinal geohelminths. Also, bronchial asthma was increased in industrialized countries ${ }^{[21] .}$

The present work results revealed that the overall rate of toxocariasis in all studied children was $11.67 \%$ [ $15 \%$ in asthmatic children, $7.5 \%$ in children with skin disease, and $12.5 \%$ in children with unexplained neurological manifestations]. The most significant associated factor with toxocariasis was contact with pets [dogs and cats]. The most significant associated clinical manifestations were chronic urticaria, lymph node involvement, and eosinophilia.

Incidence and prevalence ratios of Toxocara canis infections are still unknown in humans. However, seroepidemiological trials revealed different results depending on the studied population characteristics and study area[21]. Inconsistent with the results of the present work, Burak Selek et al.[22] showed that "Toxocara canis may stimulate chronic urticaria, as they found $17.8 \%$ seropositivity [higher than the present work and could be attributed to different inclusion criteria and sample size] in 73 patients with chronic urticaria and none in 109 healthy subjects". In tropical countries, the patients can complain of dermatological complications due to this parasitic infestation.

In a case series, skin problems are as high as $43 \%[23]$. Interestingly, Gavignet et al.[24] reported that they didn't doubt that Toxocara canis infection is a causative factor of chronic urticaria. They added Toxocara canis infection could be associated with other dermatological problems such as chronic pruritus and miscellaneous eczema. Demirci et al..25] found that Toxocara canis antibody positivity was $29 \%$ $[n=62]$ on chronic urticaria patients in their study. Humbert et al.[26] investigated the relation of Toxocara canis seropositivity and different skin manifestations in 653 patients. Toxocara canis antibodies were found positive in $38.1 \%$ of 21 prurigo patients, $15.4 \%$ in 52 patients with itching, $19.5 \%$ in 128 chronic urticaria patients, and $18.6 \%$ in 72 eczema patients, which indicated a significant relation between Toxocara antibody positivity and skin problems.

According to Gavignet et al.[24] study, eosinophilia could be the sole reason for the development of skin manifestations explained by the subsequent release of cutaneous chemotactic factors by eosinophils. Another explanation is the histamine release due to the activity of proteinase of Toxocara canis larval excretory-secretory [TES] antigens.

On the other side, there was no significant difference in sex distribution between positive 
and negative tests for anti-Toxocara antibodies. These results are consistent with Fragoso et al.[27] who studied children at their school entry for toxocariasis. Other studies show no association between sex and risk of toxocariasis ${ }^{[18,28]}$. These results were agreed with Badawey et al.[20], in Zagazig, Sharkia, Egypt, there was no significant difference between toxocariasis and sexes.

The present work results indicated that contact with pets is a significant association for toxocariasis. These results are comparable to previous literature. Parks and green areas inside the cities can be highly contaminated with Toxocara eggs because of walking pets. Dog shelters and pet shops could be the nesting place for adult forms of Toxocara. Feeding cats or dogs at home or soil-eating habits is also an important risk factor for toxocariasis ${ }^{[29-30]}$. Burak-Selek et al.[22] demonstrated that Toxocara canis seropositivity was much higher in patients with dog feeding history than the others. Other studies yield similar results[31-32]. On the other side, Fan et al. ${ }^{[33]}$ observed that a high prevalence of toxocariasis occurred similarly in individuals who had contact with dogs and those who had not and thus suggested that both groups present the same risk for infection by Toxocara canis.

The present study results come in agreement with Kamuyu et al.[34] who studied the potential link between epilepsy and parasitic infections. Their findings showed an association between Toxocara canis exposure as well as higher values of Toxocara canis antibodies and the presence of active convulsive epilepsy. The link between Toxocara canis seropositivity and epilepsy was further examined and suggested that toxocariasis may be a cofactor in the development of epilepsy[35]. A meta-analysis by Quattrocchi et al.[17] included 7 case-control trials, including subjects with age range 1 to 17 years for different countries [Americas, Europe, and Africa], supported the presence of a positive link between Toxocara canis seropositivity and epilepsy. Another more recent meta-analysis by Luna et al.[36] confirmed a positive association between Toxocara seropositivity and epilepsy. Pinelli and Aranzamendi[37] hypothesized the link between asthma and Toxocara canis, based on some experimental and epidemiological studies suggested that the infection with Toxocara canis could contribute to the development of allergy including asthma, Toxocara canis role was considered an important risk factor for asthma and other allergic disorders. However, the debate continues; some researchers suggest that parasitic infection even protects against asthma development [38], others showed that parasitic infection predisposes and could cause or trigger bronchial asthma[39].

The induction of a Th2 type of immune response characterized by the production of high levels of $\operatorname{lgE}$ and Eosinophilia is a shared immunological pathway in allergic diseases and Toxocariasis ${ }^{[40]}$. A study by Gonzalez-Quintela et al. [41] on 134 subjects with Toxocara exposure showed an intriguing interaction between Toxocara exposure and allergic sensitization total serum lgE levels and blood eosinophil counts. In a systematic review by Aghaei et al.[42] reviewing 17 studies, an increased risk for asthma was observed in children with Toxocara infection seropositivity $[O R=1.91]$. Other reports suggested that allergic manifestations, such as asthma, may be a consequence of parasitic infections ${ }^{[31,43]}$.

The current study results agree with that obtained by Badawey et al.[20] in Zagazig, Sharkia, Egypt, who reported that $17 \% \%$ of toxocariasis was present in asthmatic patients and $10 \%$ in controls. Also, ElTantawy et al.[7] reported in Mansoura, Dakahlia, Egypt, $42 \%$ of toxocariasis was found in asthmatic patients and $8 \%$ in controls. On the other side, Sharghi et al. ${ }^{[44]}$ did not find any association between Toxocara seropositivity and asthma among 95 asthmatic and 229 non-asthmatic children, probably due to the lower number of asthmatic cases in that study.

Conclusion: The association between Toxocara canis infection from one side and allergic diseases such as bronchial asthma, chronic urticaria, cryptogenic epilepsy, and focal neurological lesions gives an important clue to the cause of these diseases in the absence of other clear underlying cause. The results shown 
in the present work suggest a strong causeeffect relationship. Contact with pets was the major determinant risk factor explaining infection acquisition after exposure. Prospective cohort studies were warranted to further investigate this cause-effect relationship and define effective preventive and therapeutic measures.

Financial and Non-Financial Relationships and Activities of Interest

None

\section{REFERENCES}

1. Macpherson $\mathbf{C N}$. The epidemiology and public health importance of toxocariasis: a zoonosis of global importance. Int J Parasitol. 2013; 43 [12-13]:9991008. doi: 10.1016/j.jpara.2013.07.004.

2. Shahat SA, Mohammad KA, Saad MY, Emran TM, Mohamed SA, Elshahat ME. A Clinico-Seroepidemiological Evaluation of Toxocariasis in Asthmatic Egyptian Children. Egy J Hospital Med 2019; 2019; 76 [5]: 4195-4201.

3. Lötsch F, Vingerling R, Spijker R, Grobusch MP. Toxocariasis in humans in Africa - A systematic review. Travel Med Infect Dis. 2017 Nov-Dec;20:1525. doi: 10.1016/j.tmaid.2017.10.009.

4. Hotez PJ, Wilkins PP. Toxocariasis: America's most common neglected infection of poverty and a helminthiasis of global importance? PLoS Negl Trop Dis. 2009; 3 [3]: e400. doi: 10.1371/journal.pntd. 0000400 .

5. Azira NM, Zeehaida M. A case report of ocular toxocariasis. Asian Pac J Trop Biomed. 2011;1 [2]: 164-5. doi: 10.1016/S2221-1691[11]60018-X.

6. Zibaei M, Sadjjadi SM, Jahadi-Hosseini SH. Toxocara cati larvae in the eye of a child: a case report. Asian Pac J Trop Biomed. 2014; 4 [Suppl 1]: S53-5. doi: 10.12980/APJTB.4.2014C1281.

7. Tantawy NL, EINahas HA, El-Assmy MM, Alsalem A M. Clinicosero-epidemiological evaluation of toxocariasis in asthmatic pediatric children in Mansoura city in Egypt. Arch Clin Microbiol 2013; 4 [4]: 3. doi: 10.3823/271

8. Ma G, Holland CV, Wang T, Hofmann A, Fan CK, Maizels RM, Hotez PJ, Gasser RB. Human toxocariasis. Lancet Infect Dis. 2018;18[1]:e14-e24. doi: 10.1016/S1473-3099[17]30331-6.

9. El-Sayed NM, Ramadan ME. Toxocariasis in children: an update on clinical manifestations, diagnosis and treatment. J Pediatr Infect Dis. 2019; 12:222-227. DOI: 10.1055/s-0037-1603496

10. Pawlowski Z. Toxocariasis in humans: clinical expression and treatment dilemma. J Helminthol. 2001; 75 [4]: 299-305. doi: 10.1017/s0022149x01 000464.

11. Walsh MG, Haseeb MA. Reduced cognitive function in children with toxocariasis in a nationally representative sample of the United States. Int J Parasitol. 2012;42[13-14]:1159-63. doi: 10.1016/ j.jpara 2012.10.002.

12. Cooper PJ. Toxocara canis infection: an important and neglected environmental risk factor for asthma? Clin Exp Allergy. 2008 Apr;38[4]:551-3. doi: 10.1111/j.1365-2222.2008.02934.x.

13. Momen T, Esmaeil N, Reisi M. Seroprevalence of ToxocaraCanis in Asthmatic Children and its Relation to the Severity of Diseases - a Case-Control Study. Med Arch. 2018 Jun;72[3]:174-177. doi: 10. 5455/medarh.2018.72.174-177.

14. Ahn SJ, Ryoo NK, Woo SJ. Ocular toxocariasis: clinical features, diagnosis, treatment, and prevention. Asia Pac Allergy. 2014 Jul;4[3]:134-41. doi: 10.5415/apallergy.2014.4.3.134.

15. Moreira GM, Telmo Pde L, Mendonça M, Moreira AN, McBride AJ, Scaini CJ, Conceição FR. Human toxocariasis: current advances in diagnostics, treatment, and interventions. Trends Parasitol. 2014;30[9]:456-64. doi: 10.1016/j.pt. 2014.07.003.

16. Nunes C, Pereira AM, Morais-Almeida M. Asthma costs and social impact. Asthma Res Pract. 2017 Jan 6; 3:1. doi: 10.1186/s40733-016-0029-3.

17. Quattrocchi G, Nicoletti A, Marin B, Bruno E, DruetCabanac M, Preux PM. Toxocariasis and epilepsy: systematic review and meta-analysis. PLoS Negl Trop Dis. 2012; 6[8]: e1775. doi: 10.1371/ journal. pntd.0001775.

18. Rubinsky-Elefant G, da Silva-Nunes M, Malafronte RS, Muniz PT, Ferreira MU. Human toxocariasis in rural Brazilian Amazonia: seroprevalence, risk factors, and spatial distribution. Am J Trop Med Hyg. 2008 Jul; 79[1]:93-8. PMID: 18606770.

19. Dal T, Ciçek M, Uçmak D, Akkurt M, Tekin A, Dal MS, Tekin R, Kalkanl ST. Seroprevalence of IgG anti-Toxocara canis antibodies and anti-Fasciola sp. antibodies in patients with urticaria. Clin Ter. 2013; 164[4]:315-7. doi: 10.7417/CT.2013.1579.

20. Badawey Maha S, Fathy Ghada M, Abdelrahman Sara A, Dalia A. Relation between Toxocara infection, atopy and asthmatic bronchitis children in Zagazig University Hospitals. J Egy Soc Parasitol 2018; 48 [1]: 93 - 100. DOI: 10.12816/jesp. 2018. 77030

21. Cassenote AJ, Lima AR, Pinto Neto JM, RubinskyElefant G. Seroprevalence and modifiable risk factors for Toxocara spp. in Brazilian schoolchildren. PLoS Negl Trop Dis. 2014 May 29; 8[5]: e2830. doi: 10.1371/journal.pntd.0002830.

22. Burak Selek M, Baylan O, Kutlu A, Özyurt M. 
Toxocara Canis IgG Seropositivity in Patients with Chronic Urticaria. Iran J Allergy Asthma Immunol. 2015 Aug;14[4]:450-6. PMID: 26547714.

23. Van Den Broucke S, Kanobana K, Polman K, Soentjens $P$, Vekemans $M$, Theunissen $C$, et al. Toxocariasis diagnosed in international travelers at the Institute of Tropical Medicine, Antwerp, Belgium, from 2000 to 2013. PLoS Negl Trop Dis 2015; 9[3]: e0003559. doi: 10.1371/journal. pntd. 0003559

24. Gavignet B, Piarroux R, Aubin F, Millon L, Humbert P. Cutaneous manifestations of human toxocariasis. J Am Acad Dermatol. 2008 Dec; 59 [6]:1031-42. doi: 10.1016/j.jaad.2008.06.031.

25. Demirci M, Yildirim M, Aridogan BC, Baysal V, Korkmaz M. Tissue parasites in patients with chronic urticaria. J Dermatol. 2003 Nov;30[11]:77781. doi: 10.1111/j.1346-8138.2003.tb00477.x.

26. Humbert $P$, Niezborala $M$, Salembier R, Aubin F, Piarroux R, Buchet S, Barale T. Skin manifestations associated with toxocariasis: a casecontrol study. Dermatology. 2000;201[3]:230-4. doi: 10.1159/000018493.

27. Fragoso RP, Monteiro MB, Lemos EM, Pereira FE. Anti-Toxocara antibodies detected in children attending elementary school in Vitoria, State of Espírito Santo, Brazil: prevalence and associated factors. Rev Soc Bras Med Trop. 2011; 44 [4]: 4616. doi:10.1590/s0037-86822011000400012.

28. Sadjjadi SM, Khosravi M, Mehrabani D, Orya A. Seroprevalence of toxocara infection in school children in Shiraz, southern Iran. J Trop Pediatr. 2000;46[6]:327-30. doi: 10.1093/tropej/46.6.327.

29. Despommier D. Toxocariasis: clinical aspects, epidemiology, medical ecology, and molecular aspects. Clin Microbiol Rev. 2003 Apr; 16[2]:265-72. doi: 10.1128/cmr.16.2.265-272.2003.

30. Mizgajska $H$. Eggs of Toxocara spp. in the environment and their public health implications. J Helminthol. 2001;75[2]:147-51. PMID: 11520438.

31. Won KY, Kruszon-Moran D, Schantz PM, Jones JL. National seroprevalence and risk factors for Zoonotic Toxocara spp. infection. Am J Trop Med Hyg. 2008 Oct;79[4]:552-7. PMID: 18840743.

32. Santarém VA, Leli FN, Rubinsky-Elefant G, Giuffrida R. Protective and risk factors for toxocariasis in children from two different social classes of Brazil. Rev Inst Med Trop Sao Paulo. 2011 Mar-Apr;53[2]:66-72. doi: 10.1590/s0036-466 52011000200002.

33. Fan CK, Hung CC, Du WY, Liao CW, Su KE. Seroepidemiology of Toxocara canis infection among mountain aboriginal schoolchildren living in contaminated districts in eastern Taiwan. Trop Med Int Health. 2004;9[12]:1312-8. doi: 10.1111/j.13653156.2004.01332.x.

34. Kamuyu G, Bottomley C, Mageto J, Lowe B, Wilkins PP, Noh JC, et al. Study of epidemiology of epilepsy in demographic sites [SEEDS] group. Exposure to multiple parasites is associated with the prevalence of active convulsive epilepsy in subSaharan Africa. PLoS Negl Trop Dis 2014; 8: e2908. doi: 10.1371/journal.pntd.0002908.

35. Zibaei M, Firoozeh F, Bahrami P, Sadjjadi SM. Investigation of anti-Toxocara antibodies in epileptic patients and comparison of two methods: ELISA and Western blotting. Epilepsy Res Treat. 2013; 2013: 156815. doi: 10.1155/2013/156815.

36. Luna J, Cicero CE, Rateau G, Quattrocchi G, Marin B, Bruno $E$, et al. Updated evidence of the association between toxocariasis and epilepsy: Systematic review and meta-analysis. PLoS Negl Trop Dis 2018; 12[7]: e0006665. doi: 10.1371/ journal.pntd.0006665

37. Pinelli E, Aranzamendi C. Toxocara infection and its association with allergic manifestations. Endocr Metab Immune Disord Drug Targets. 2012; 12 [1]: 33-44. doi: 10.2174/187153012799278956.

38. Smits HH, Everts B, Hartgers FC, Yazdanbakhsh M. Chronic helminth infections protect against allergic diseases by active regulatory processes. Curr Allergy Asthma Rep. 2010 Jan;10[1]:3-12. doi: 10.1007/s11882-009-0085-3.

39. Nourian AA, Amiri M, Ataeian A, Haniloo A, Mosavinasab SN, Badali H. Seroepidemiological study for toxocariasis among children in Zanjannorthwest of Iran. Pak J Biol Sci. 2008; 11 [14]:18447. doi: 10.3923/pjbs.2008.1844.1847.

40. Fitzsimmons CM, Falcone FH, Dunne DW. Helminth Allergens, Parasite-Specific IgE, and Its Protective Role in Human Immunity. Front Immunol. 2014; 5:61. doi: 10.3389/fimmu. 2014. 00061.

41. Gonzalez-Quintela A, Gude F, Campos J, Garea MT, Romero PA, Rey J, et al. Toxocara infection seroprevalence and its relationship with atopic features in a general adult population. Int Arch Allergy Immunol. 2006;139[4]:317-24. doi: 10. 1159/000091603.

42. Aghaei S, Riahi SM, Rostami A, Mohammadzadeh I, Javanian M, Tohidi E, Foroutan M, Esmaeili Dooki M. Toxocara spp. infection and risk of childhood asthma: A systematic review and metaanalysis. Acta Trop. 2018 Jun;182:298-304. doi: 10.1016/j.actatropica.2018.03.022.

43. Amoah AS, Boakye DA, van Ree R, Yazdanbakhsh M. Parasitic worms and allergies in childhood: insights from population studies 2008-2013. Pediatr Allergy Immunol. 2014;25[3]:208-17. doi: 10.1111/ pai.12174.

44. Sharghi N, Schantz PM, Caramico L, Ballas K, Teague BA, Hotez PJ. Environmental exposure to Toxocara as a possible risk factor for asthma: a clinic-based case-control study. Clin Infect Dis. 2001 Apr 1;32[7]:E111-6. doi: 10.1086/319593. 


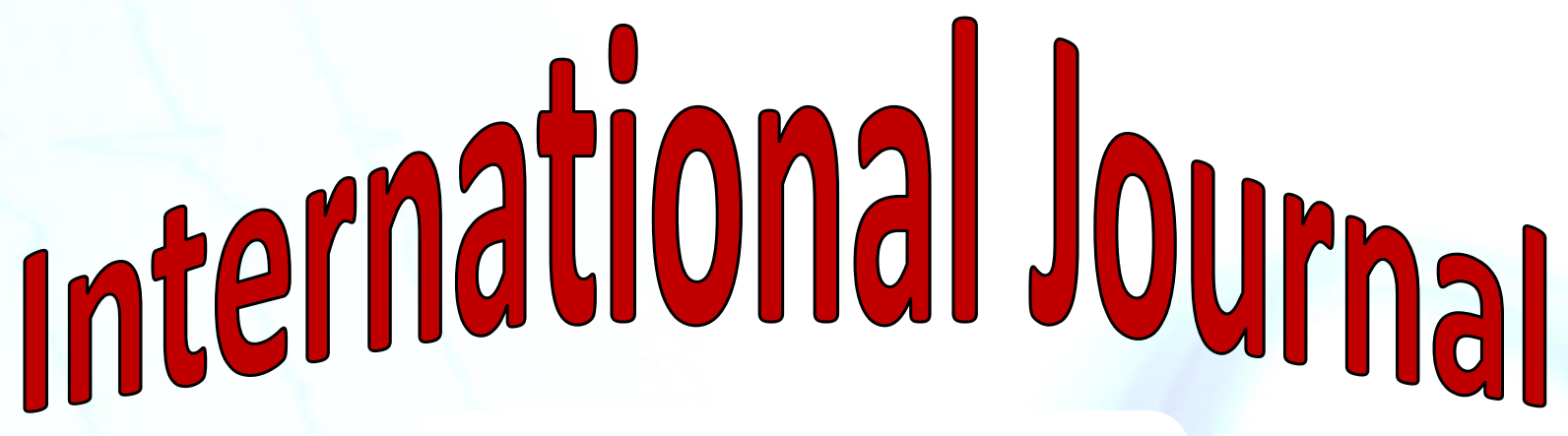

https://ijma.journals.ekb.eg/

Print ISSN: 2636-4174

Online ISSN: 2682-3780

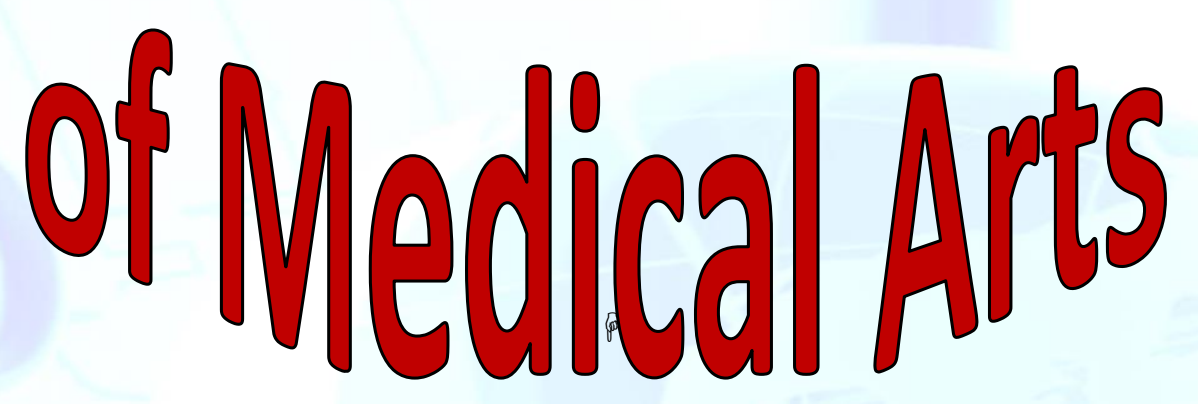

